\title{
Comparing the Effectiveness of Motor Control Exercises versus Mckenzie Exercises for Work Related Back Pain
}

\author{
Tanvi Tanna, Senthilkumar Thiyagarajan, Prabhu Chinna Gounder \\ Department of Musculoskeletal and Sports, The Oxford College of Physiotherapy, Bangalore, India \\ Email: tanvitanna57@gmail.com
}

Received 21 July 2016; accepted 26 August 2016; published 29 August 2016

Copyright (C) 2016 by authors and Scientific Research Publishing Inc.

This work is licensed under the Creative Commons Attribution International License (CC BY).

http://creativecommons.org/licenses/by/4.0/

c) (i) Open Access

\begin{abstract}
Background: Work related low back pain has been identified as a one of the most costly disorders among the worldwide working population. This condition was highly prevalent that approximately $85 \%$ patients having back pain were brought on by prolonged sitting. With the rapid development of modern technology, sitting has now become the most common posture in today's workplace. Idea of using motor control learning approach provides the optimal control and coordination of the spine. The McKenzie evaluation was received using repeated movements and sustained positions. Therefore high quality randomized clinical trial was required to compare the effectiveness of these treatments for work related low back pain. Objectives: To compare the effectiveness of motor control exercises and McKenzie exercises in reducing pain and disability in work related low back pain. Method: The study included 40 subjects with work related low back pain due to prolonged sitting. They were randomly allocated into two groups (Group A and Group B). Group A was treated with motor control exercises and group B was treated with McKenzie exercises for 4 weeks. Results: Both the groups have shown statically significant improvement in vas with $p<$ 0.0001 and ODI with $p<0.0001$. When the comparison was done after the 4 weeks, the percentage of improvement in group A was much higher than Group B. Conclusion: The study concluded that motor control exercises have shown statically and clinically significant improvement in reducing pain and disability when compared to McKenzie exercises among work related low back pain subjects.
\end{abstract}

\section{Keywords}

Low Back Pain (LBP), Oswestry Disability Index (ODI), Motor Control Exercise (MCE), McKenzie Exercise (MKZ), Visual Analogue Scale (VAS) 


\section{Introduction}

Low back pain is an important health problem with significant consequences from socio economical point of view and is associated with high costs, work absenteeism and disability. In modern society due to increase of sedentary jobs, one of the major causes is work related low back pain. Work-related low back disorders, covering both low back pain and low back injuries, are significant and increasing problem among the worldwide working population. Lack of spinal motion as a provocative factor seems to correspond with what has been found in analysis of patient with LBP: $85 \%$ found pain was brought on by prolonged sitting, $73 \%$ by standing, but only $23 \%$ by walking and $15 \%$ by cycling [1]. During sitting, a prolonged compression force may increase the risk of disc problems, or the continuous activity of some type I motor units of back muscles may contribute to the development of fatigue [2] [3]. With the rapid development of modern technology, sitting has now become the most common posture in today's workplace [4]. Risk of low back pain is significantly higher when exposure time is $>42$ hours/week in sitting workers [5].

Treatment for low back pain may last from a few weeks to several months and usually takes multimodality approach. Exercise is one method that can reduce muscle imbalance, improve resilience to muscle fatigue, and address reactivity and strength.

Motor control exercise, also known as specific stabilization exercise, is a new form of exercise for back pain that has gained the attention of researchers and health practitioners over the past decade. The exercise focuses on regaining control of the trunk muscles. Previous studies of patients with low back pain have shown that they are unable to properly control these muscles [6].

McKenzie method consists of 3 steps: evaluation, treatment and prevention. The evaluation is received using repeated movements and sustained postures. The aim of this exercise is to elicit a pattern of pain responses, called centralization. The aims of the therapy are: reducing pain, centralization of symptoms and the complete recovery of pain [7]-[9].

Prolonged sitting which cause structural changes in soft tissue, muscular weakness around the lower back area leads to mechanical back pain. A physiotherapist should treat causative factors and long lasting benefits are to be maintained. So current study would find out the effectiveness of motor control exercises versus McKenzie exercises in work related low back disorder subjects.

\section{Materials and Methodology}

Forty subjects (20 in each) were chosen based on inclusion and exclusion criteria (Table 1) from outpatient department of the oxford college of physiotherapy, physiotherapy clinics in and around Bangalore and from community settings in and around Bangalore. All the subjects were sitting job worker ( $>8$ hours/day), having back pain $\geq 3$ months without radiation, disability score on ODI up to $40 \%$ (minimum to moderate disability) both the genders (male and female) between the ages of 25 - 40 years were eligible for the study. A total of 40 subjects were divided equally into two groups by random method. Group A $(n=20)$ and Group B $(n=20)$. Group Amotor control exercise and Group B-McKenzie exercise was given for alternate day per week for 4 weeks.

\section{Table 1. Selection criteria.}

\begin{tabular}{cc}
\hline INCLUSION CRITERIA & EXCLUSION CRITERIA \\
\hline Prolonged sitting workers(chair sitting) (>8 hours) & $\begin{array}{c}\text { Any neurological or cardiovascular abnormalities } \\
\text { which is contraindicated for exercise }\end{array}$ \\
Age group 25 - 40 years & Undergone any back surgeries \\
Low back pain $>3$ months & Any tumors in the spine \\
Low back pain without radiation & Pregnant women \\
Both genders & Subjects who are not willing to participate \\
Patients with minimum to moderate disability & \\
(up to 40\%) on Oswestry disability questionnaire
\end{tabular}




\subsection{Procedure}

\subsubsection{Motor Control Exercise}

At the first session, participants were comprehensively assessed by the physical therapist. 20 minute training session was given on the first day. This included three training activities which helped in increasing abdominal muscle awareness. Abdominal breathing in supine position was used to provide an increase general awareness of the abdominal muscles and breathe control. Quadruped abdominal hollowing in which gravity was presumed to provide resistance to transverse abdomen is contraction while the subjects attempted to hollow the abdomen. The third activity was abdominal hollowing (drawing in) in hook-lying position. This was done using stabilizer biofeedback unit. The three chamber pressure cell of stabilizer placed beneath back at the level of umbilicus. The cuff was inflated up to $40 \mathrm{mmhg}$ and the aneroid meter was handed to the subject so that it is visible to the subject. Then, the subject was instructed to hollow the abdomen and increase or maintain the pressure at 40 mmhg $( \pm 10$ mmhg) for 10 seconds.

Then the exercises follow the sequence:

- Breathing exercises in hook lying position: 10 repetitions $10 \mathrm{sec}$ hold (Figure 1(a)),

- Abdominal draw in with pressure biofeedback: 10 repetition 10 sec hold (Figure 1(b)),

- Quadruped position and abdominal draw in: 10 repetition 10 sec hold (Figure 1(c)),

- Abdominal draw in with heel slide: 10 repetition 10 sec hold (Figure 1(d)),

- Abdominal draw in with hip abduction: 10 repetition $10 \mathrm{sec}$ rest (Figure 1(e)),

- Quadruped alternate arm and leg lift with abdominal draw in: 10 repetition 10 sec rest (Figure 1(f)).

2 minutes of rest given after every exercise.

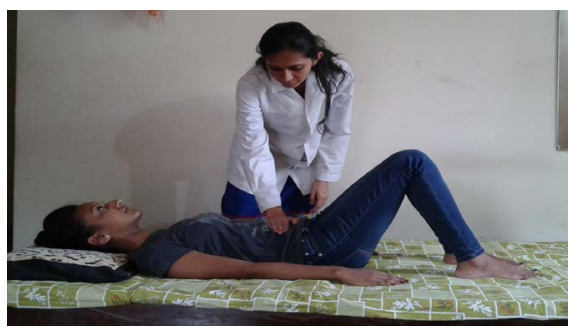

(a)

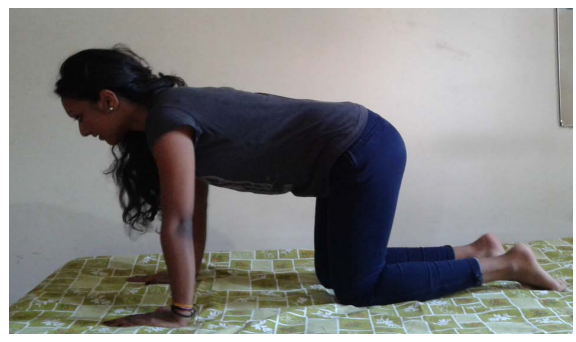

(c)

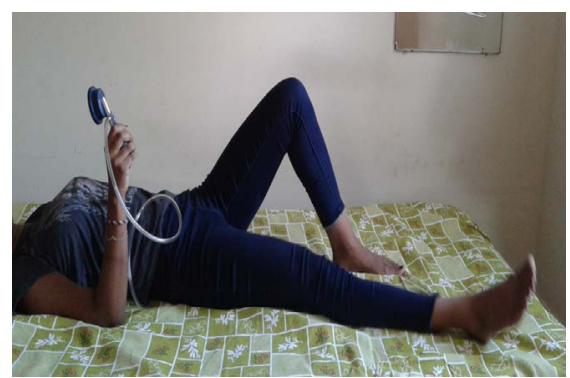

(e)

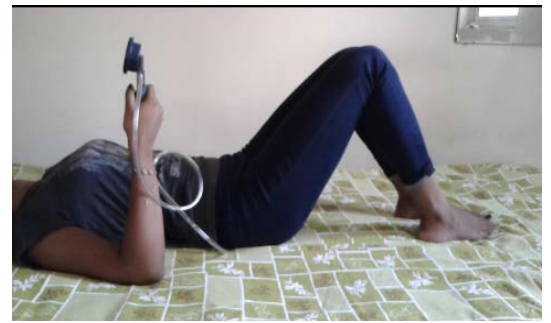

(b)

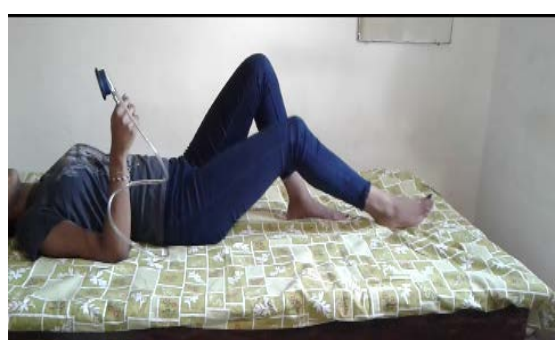

(d)

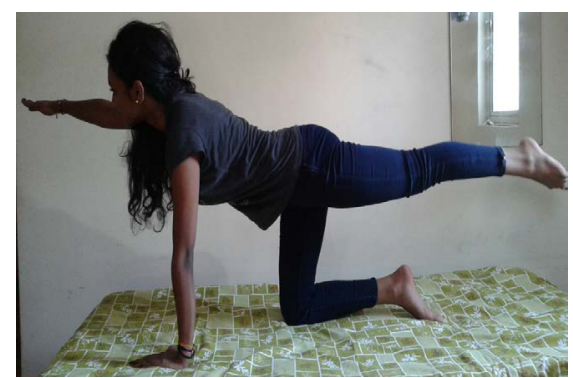

(f)

Figure 1. (a): Breathing exercises in hook lying position; (b): Abdominal draw in with pressure biofeedback; (c): Quadruped position and abdominal draw in; (d): Abdominal draw in with heel slide; (e): Abdominal draw in with hip abduction; (f): Quadruped alternate arm and leg lift with abdominal draw in. 


\subsubsection{McKenzie Exercise}

The McKenzie group participants were treated based on their history and response to movement examination by McKenzie evaluation form.

Exercises include: extension exercises and flexion exercises. The extension type exercise was performed in prone and standing position and flexion type exercise in supine and sitting position.

The final position of each exercise was maintained for 10 seconds for in each repetition. In each session 10 repetition of each exercise were performed. Exercises include:

- Lie on stomach with pillow \& arm close to body take a deep breath-relaxation for 5 minutes,

- Lie on stomach elbow under the shoulder as resting on the forearm 10 repetitions with 10 hold,

- Lie on stomach hand under shoulder, elbow straight back raise upward as far as possible 10 repetitions 10 sec hold,

- In standing hands on low back bending backward as far as possible 10 repetition with 10 sec hold.

All the data was analyzed on an intension to treat basis, using SPSS software version 19. Paired t-test was used within groups. Independent t-test was used in between groups. Outcome measures were the two tools i.e. Visual analogue scale and Oswetry disability index.

\section{Results}

The study included 40 subjects with mean age29.4and SD of 3.90 shown in Table 2 (Distribution of mean age), Figure 2(a) and Figure 2(b). The group A had mean age of $28.9 \pm 3.90$ while that of group B was $29.9 \pm 3.93$.

The t-test for paired sample was used between pre and post test of the VAS and ODI of Group A. It was seen in Table 3 (paired sample statistics Group A) and Figure 3 the mean of VAS before motor control exercise was 5.25 and it was decreased to 1.5 having p value 0.0001 , the mean of ODI before motor control exercise was 29.3 and it was decreased to 15 having p value 0.0001 which were significant difference between the two means.

The $t$ test for Paired sample was used between pre and post test of VAS and ODI for the group B.

It was seen in Table 4 (Paired sample statistics of Group B) and Figure 4, the mean of Vas before McKenzie exercise was 5.05 and it was decreased to 2.25 having p value 0.0001 , the mean of ODI before McKenzie exercise was 27.3 and it was decreased to 23.4 having p value 0.0001 which were significant difference between the two means.

There was significant difference between the two means of VAS on GROUP A versus GROUP Bas shown in Table 5 the group A 5.25 vs 1.5 while group B 5.05 vs 2.25 .

There was significant difference between the two means of ODI on GROUP A versus GROUP B as shown in Table 6 the group A 29.3 vs 15 while group B 27.3 vs 23.1 .

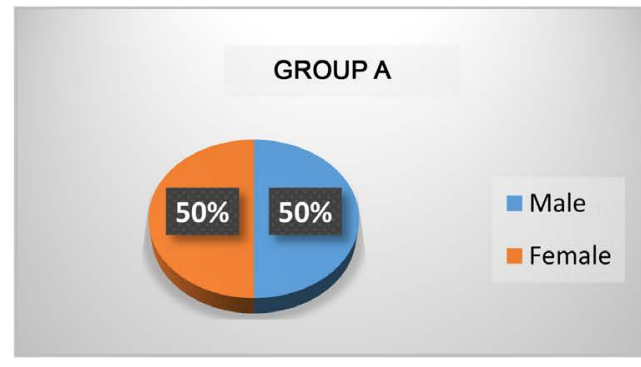

(a)

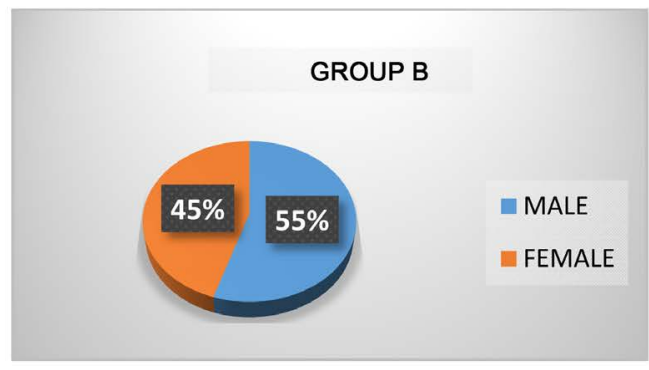

(b)

Figure 2. (a): Distribution of mean age in Group A; (b) Distribution of mean age in Group B.

Table 2. Distribution of mean age.

\begin{tabular}{cccc}
\hline SUBJECT AGE & N & MEAN & SD \\
\hline Total & 40 & 29.4 & 3.90 \\
Group A & 20 & 28.9 & 3.90 \\
Group B & 20 & 29.9 & 3.93 \\
\hline
\end{tabular}


GROUP A

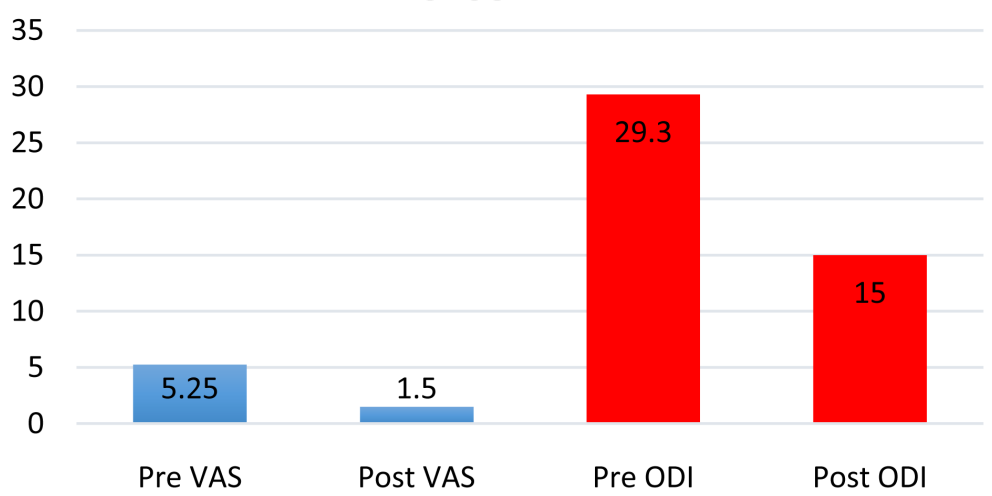

Figure 3. Paired sample statistics Group A.

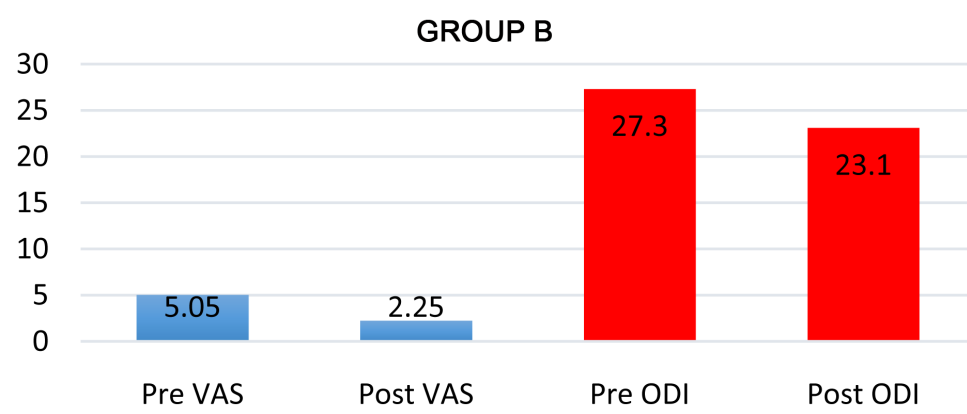

Figure 4. Paired sample statistics of Group B.

Table 3. Paired sample statistics of Group A.

\begin{tabular}{rccccc}
\hline & N & Mean & SD & t value & p value \\
\hline Pre VAS & 20 & 5.25 & 0.91 & 18.42 & 0.0001 \\
Post VAS & 20 & 1.5 & 0.83 & & 0.0001 \\
Pre ODI & 20 & 29.3 & 0.75 & 11.28 & 3.81 \\
Post ODI & 20 & 15 & & \\
\hline
\end{tabular}

Table 4. Paired sample statistics of Group B.

\begin{tabular}{rccccc}
\hline & N & MEAN & SD & t value & p value \\
\hline Pre VAS & 20 & 5.05 & 0.99 & 11.85 & 0.0001 \\
Post VAS & 20 & 2.25 & 1.06 & & 0.0001 \\
Pre ODI & 20 & 27.3 & 6.37 & 6.04 & \\
Post ODI & 20 & 23.1 & 4.52 & & \\
\hline
\end{tabular}

Table 5. VAS for pain analysis.

\begin{tabular}{ccccc}
\hline & Pre Group A & Pre Group B & Post Group A & Post Group B \\
\cline { 2 - 5 } VAS & 5.25 & 5.05 & 2.5 & 2.412 \\
t value & & 0.6618 & & 0.0208 \\
\hline p value & & 0.5121 & & \\
\hline
\end{tabular}


Table 6. ODI analysis (Oswestry disability index).

\begin{tabular}{|c|c|c|c|c|}
\hline \multirow{2}{*}{ ODI } & Pre Group A & Pre Group B & Post Group A & Post Group B \\
\hline & 29.3 & 27.3 & 15 & 23.1 \\
\hline $\mathrm{t}$ value & \multicolumn{2}{|c|}{0.941} & \multicolumn{2}{|c|}{6.129} \\
\hline $\mathrm{p}$ value & \multicolumn{2}{|c|}{0.3526} & \multicolumn{2}{|c|}{0.0001} \\
\hline
\end{tabular}

Interpretation of Result:

The study was conducted on 40 subjects diagnosed with work related low back pain to compare the effectiveness of motor control and McKenzie exercise. The patients are randomly allocated into two groups with 20 each. In which group A was given MCE. Group B was given MKZ. Thus the results of the present study show that there is significant statistical difference between the groups.

\section{Discussion}

The present study was carried out to compare and find out the effectiveness of motor control exercise versus McKenzie exercise for work related low back disorder.

Prevalence:

In the study estimated percentage of work related low back pain is approximately $30 \%$ from the screened population. Most of the subjects were having work experience more than one year were working for more than 8 hours so it can be stated that they were exposed to prolonged sitting and awkward postures. Homogeneity of male and female ratio was maintained in current study. The results of the study showed that pain and disability decreased in both the groups. But disability was significantly decreased in motor control exercise group. The findings are consistent with the findings of previous studies in terms of improvement in pain and function following the application of motor control exercise.

Interventions for This Study:

Group A received Motor control exercises. There is a significant change in pain and disability was seen in motor control exercises group several reasons can be-Motor control training change trunk muscle behaviour during functional task. The mechanism includes reduced load and improved quality of movement [10]. This approach targets the Specific Deep stabilizing muscles of lower back region, multifidus, transverse abdominis and pelvic floor. Particularly these become dysfunctional after experiencing back pain. So the function and dysfunction of these local muscles is important to treat the back pain. Reprogramming the brain for optimal stabilization targets right muscle-for-right task [11]. The control of spine equilibrium and mechanical stability however, requires appropriate muscle recruitment and timing. Muscular dysfunction and motor control errors in maintaining spine stability have been suggested as possible causes of some low back disorders and chronic back pain. Group $\mathrm{B}$ received McKenzie exercises. Considering the above mention points, for motor control group, pain reduction in the McKenzie group might have occurred due to other causes without changes in the thickness of abdominal and MF muscles. Peterson T. et al. did one year follow up comparison of the effectiveness of McKenzie treatment and strengthening training for patients with chronic low back pain: outcome and prognostic factors and study revealed that this approach was focused on sustained postures or repeated movements, and pain reduction might have been due to postural correction [12]. Another important factor was the intensity and duration of the intervention used for the study. The intervention lasted for period of 4 weeks and was administered for alternate days in a week for 30 - 45 minutes. Muscle hypertrophy typically occurs after 8 - 12 weeks intensive strengthening exercise. Thus, we proposed that short duration of the present study and effect of neuromuscular adaptation led to changes in some of the outcomes [13] [14]. According to this Study both the groups Group A (MCE) and Group B (MKZ) showed significant improvement in VAS, and ODI. But in comparison between the groups, the MCE group showed more improvement in above parameters. This reveals that MCE seems to be having an additional effect towards reducing pain and disability in patients suffering from work related low back disorder. The result of the this study shows that because of working in awkward posture for prolonged time, wrong ergonomics, more working hours and inappropriate working environment there was about $30 \%$ of the population from screened population having work related low back pain. 


\section{Outcome Measures:}

There was no established gender difference in the prevalence of work related low back disorder in this study. Also, there was no marked mean age difference found between the groups. The outcome measures used for the study were VAS and ODI. Both the outcome showed a statistically significant difference within the group but when compared between the groups motor control exercise group showed statically and clinically superior to McKenzie exercise group. Several mechanisms were proposed for this change and within short period of time desired change was obtained. It could be concluded that there was added effect of motor control exercise was seen in reducing pain and disability than McKenzie exercise.

\section{Conclusion}

Randomized clinical trial study found that subjects having work related low back disorder showed reduction in pain and disability. However, motor control exercises and McKenzie exercise show reduction in pain and disability but considerable better improvement is seen with motor control exercise, so it can be concluded that motor control exercises improves TrA and LM muscle activation and is superior in improving pain and reducing disability.

\section{Acknowledgements}

We thank to The Oxford College of Physiotherapy Review Board on Ethics for Research (TOCPTRBER) for their approval and valuable suggestion and views on this topic. Special word of thanks to participants who are all participated voluntarily in the study.

\section{Conflict of Interest}

There was No Conflict of interest.

\section{References}

[1] van Deursen, L.L.J.M. and Patijin, J. (1993) Aufwertung der "Ligamentaren Kreuzschmerzen”. Manuelle Medizin, 31, 108-110.

[2] Bernard, B.P. and Fine, L.J. (1997) Musculoskeletal Disorders and Work Place Factors. U.S. Department of Health and Human Services.

[3] Hartvigsen, J., Leboeuf, Y.C., Lings, S. and Corder, E.H. (2000) Is Sitting-While-at-Work Associated with Low Back Pain? A Systematic Critical Literature Review. Scandinavian Journal of Public Health, 28, 230-239. http://dx.doi.org/10.1177/14034948000280030201

[4] Li, G. and Haslegrave, C.M. (1999) Seated Postures for Manual, Visual and Combined Tasks. Ergonomics, 42, 10601086. http://dx.doi.org/10.1080/001401399185144

[5] Hakala, P.T., et al. (2006) Frequent Computer Related Activities Increase the Risk of Neck Shoulder and Low Back Pain in Adolescents. European Journal of Public Health, 16, No. 5.

[6] Wise, S.P. and Shadmehr, R. (2000) Motor Control. Encyclopedia of the Human Brain. Academic Press, San Diego, CA, Vol. 3, 137-157.

[7] Browder, D.A., et al. (2007) Effectiveness of an Extension-Oriented Treatment Approach in a Subgroup of Subjects with Low Back Pain: A Randomized Clinical Trail. The Scientific Journal of American Physical Therapy Association, 87, 1608-1618.

[8] Machado, L.A.C., et al. (2006) The McKenzie Method for Low Back Pain: A Systematic Review of the Literature with a Meta-Analysis Approach. SPINE, 31, E254-E262 (A1).

[9] Garcia, A., et al. (2011) Effectiveness of the Back School and McKenzie Techniques in Patients with Chronic NonSpecific Low Back Pain: A Protocol of a Randomized Controlled Trial. BMC Musculoskeletal Disorders, 12, 179 (B). http://dx.doi.org/10.1186/1471-2474-12-179

[10] Hodges, P.W. and Lorimer Moseley, G. (2003) Pain and Motor Control of Lumbopelvic Region: Effect and Possible Mechanism. Journal of Electromyography and Kinesiology, 13, 361-370. http://dx.doi.org/10.1016/S1050-6411(03)00042-7

[11] Howard, A. and Knudsen, P.T. (2009) Advance Expertise in Use of Real Time Ultra sound Imaging of Motor Control Assessment and Exercise Prescription, Certified Provider of ASTYM Treatment. 
[12] Peterson, T., et al. (2007) One Year Follow up Comparison of Effectiveness of McKenzie Treatment and Strengthening Training for Patient with Chronic Low Back Pain: Outcome and Prognostic Factor. Spine, 32, 2948-2956. http://dx.doi.org/10.1097/BRS.0b013e31815cda4a

[13] Danneels, L.A., et al. (2001) The Effect of Three Different Training Modalities on Cross Sectional Area of the Para Vertebral Muscles. Scandinavian Journal of Medicine \& Science in Sports, 11, 335-341. http://dx.doi.org/10.1034/j.1600-0838.2001.110604.x

[14] Enoka, R.M. (1997) Neural Adaptations with Chronic Physical Activity. Journal of Biomechanics, 30, 447-455. http://dx.doi.org/10.1016/S0021-9290(96)00170-4

\section{Submit or recommend next manuscript to SCIRP and we will provide best service for you:}

Accepting pre-submission inquiries through Email, Facebook, LinkedIn, Twitter, etc.

A wide selection of journals (inclusive of 9 subjects, more than 200 journals)

Providing 24-hour high-quality service

User-friendly online submission system

Fair and swift peer-review system

Efficient typesetting and proofreading procedure

Display of the result of downloads and visits, as well as the number of cited articles

Maximum dissemination of your research work

Submit your manuscript at: http://papersubmission.scirp.org/ 